\title{
Dissociating Movement from Movement Timing in the Rat Primary Motor Cortex
}

\author{
Eric B. Knudsen, ${ }^{1}$ Marissa E. Powers, ${ }^{1}$ and Karen A. Moxon ${ }^{1,2}$ \\ ${ }^{1}$ Drexel University School of Biomedical Engineering and Health Sciences and ${ }^{2}$ Drexel University College of Medicine Departments of Neurobiology and \\ Anatomy, Philadelphia, Pennsylvania 19104
}

Neural encoding of the passage of time to produce temporally precise movements remains an open question. Neurons in several brain regions across different experimental contexts encode estimates of temporal intervals by scaling their activity in proportion to the interval duration. In motor cortex the degree to which this scaled activity relies upon afferent feedback and is guided by motor output remains unclear. Using a neural reward paradigm to dissociate neural activity from motor output before and after complete spinal transection, we show that temporally scaled activity occurs in the rat hindlimb motor cortex in the absence of motor output and after transection. Context-dependent changes in the encoding are plastic, reversible, and re-established following injury. Therefore, in the absence of motor output and despite a loss of afferent feedback, thought necessary for timed movements, the rat motor cortex displays scaled activity during a broad range of temporally demanding tasks similar to that identified in other brain regions.

Key words: brain machine interface; motor cortex; rat; spinal cord injury; temporal scaling

\section{Introduction}

The timing of motor output (e.g., muscle activation that produces limb movement) enables effective interaction with the environment at millisecond to second timescales (Isomura et al., 2009; Mirabella et al., 2011). Studies report that temporal estimates of planned movements are encoded by populations of single neurons that monotonically modulate firing rate in proportion to the estimate, referred to as temporal scaling (Merchant et al., 2013a; Wittmann, 2013). Such neuronal behavior has been identified throughout the cortex (Goldman-Rakic, 1995; Crammond and Kalaska, 2000; Matell et al., 2003, 2011; Roux et al., 2003; Lebedev et al., 2004, 2008; Reutimann et al., 2004; Merchant et al., 2004a, b; 2011; Janssen and Shadlen, 2005; Merchant and Georgopoulos, 2006; Maimon and Assad, 2006; Renoult et al., 2006; Genovesio et al., 2009; Mita et al., 2009; Knudsen et al., 2012; Kim et al., 2013) and across different behavioral tasks. We recently extended this phenomena to subpopulations of neurons within the hindlimb sensorimotor cortex (HLSMC) of rats producing timed hindlimb movements (Knudsen et al., 2012). Merchant et al. (2011) showed that during a timed finger-tapping task in monkeys, four distinct patterns of scaled activity (i.e., one or more features of the trial-average neural response) emerged in a

\footnotetext{
Received May 5, 2014; revised Sept. 10, 2014; accepted 0ct. 2, 2014.

Author contributions: E.B.K. and K.A.M. designed research; E.B.K. and M.E.P. performed research; M.E.P. contributed unpublished reagents/analytic tools; E.B.K., M.E.P., and K.A.M. analyzed data; E.B.K. and K.A.M. wrote the paper.

This work was supported by Grant NS057419 from the National Institutes of Health, Grant 89500 from Shriners Hospital for Children, and Grant P113 from the Internationale Stifung fur Forschung in Paraplegie. Thanks to Anitha Manohar for discussion of the work presented here and with evaluation of the techniques used.

The authors declare no competing financial interests.

Correspondence should be addressed to Karen A. Moxon, Drexel University College of Medicine Departments of Neurobiology and Anatomy, Philadelphia, PA 19104. E-mail: karen.moxon@drexel.edu.

DOI:10.1523/JNEUROSCI.1816-14.2014

Copyright $\odot 2014$ the authors $\quad 0270-6474 / 14 / 3415576-11 \$ 15.00 / 0$
}

context-dependent fashion. Given the potential utility of these temporally specific signals in brain-machine interface (BMI) applications for the restoration of volitional movements, our first goal was to determine whether temporally scaled timing patterns of activity similar to those used by neurons in primate premotor cortex are used by neurons in the rat hindlimb cortex during a temporal interval task.

Our second goal was to determine the necessity of motor output and afferent feedback on the encoding of temporal intervals. On the one hand, the effect of timing context (Coull and Nobre, 2008) described previously (Renoult et al., 2006; Merchant et al., 2011; Knudsen et al., 2012) has not yet been considered when estimates are made in the absence of movement, although temporally scaled firing patterns are observed in prefrontal cortex during perceptual timing tasks before movement onset (Kim et al., 2013) and in the moments leading up to visual-based interception tasks (Merchant et al., 2004a). On the other hand, the ability to appropriately time movement is thought to rely on afferent feedback (Billon et al., 1996; Scott, 2004; Stenneken et al., 2006). Previous work has shown that the ability to time periodic finger movements in a patient with no proprioceptive or tactile sensations was less reliable than that of healthy controls, but not completely lost (Billon et al., 1996). This result was supported by more recent studies during similar finger-tapping tasks (Stenneken et al., 2006) and hand-foot coordination tasks (Bard et al., 1992; Stenneken et al., 2002). Moreover, in the optimal control framework of Scott (2004), precise movement timing is achieved through ongoing sensory feedback (Scott, 2004). To reconcile these to contrary findings, our second goal was to test how the representation of timing patterns within the same subpopulations of HLSMC neurons was affected by first dissociating neural activity from motor output using a neural reward paradigm 
(NRP), and subsequently eliminating afferent feedback through a complete spinal cord injury.

Our results show that a similar range of scaled timing patterns occur in the HLSMC even in the absence of motor output. Importantly the distribution of their representation changed with changes in task context but these changes were reversible. After a complete spinal transection, timing patterns were initially lost but the same patterns were relearned with a unique distribution. These findings suggest that temporal processing, though contextually engaged, is subserved by a small number of stereotyped neural activations, and that these patterns are maintained as part of an ongoing neural representation of temporal intervals.

\section{Materials and Methods}

Overview of experimental approach. To determine whether the same four timing patterns identified previously (Merchant et al., 2011) could be identified in the rat motor cortex, single neurons were recorded while animals pressed a lever with their hindlimbs for different intervals, depending on the cue in a manner similar to previous studies on interval timing. Animals were rewarded for making the duration press that matched the cue (BC mode). Off-line, parameters of neuronal activity for each neuron were used in an unsupervised combined principal components analysis (PCA) $/ k$-means analysis to identify the different timing patterns and the proportion of cells in each group. To determine whether these timing patterns changed when motor output was dissociated from the timing task and in the absences of afferent feedback after spinal transection, animals were trained in an NRP, similar to brain-machine interface paradigms [i.e., single-trial responses of all neurons (scaled and unscaled) were decoded and the animal was rewarded if the decoder correctly identified press duration indicated by the cue]. Eventually, the lever was removed and the animal continued to be rewarded if the singletrial neural activity was correctly decoded. During the NRP, neuronal activity was saved for off-line analysis and again neurons were classified as scaled or not scaled and the proportion of neurons for each timing pattern was compared across experimental conditions (behavior: no neural decoding; NRP-b: neural decoding but the animal could press the lever; and NRP-o: neural decoding but the lever was removed). Finally the animal was transected, the same NRP (NRP-TX) was used, and the data were saved for off-line analysis to classify the neuron timing parameters and compare to the other experimental conditions. To address the first goal, since the NRP was not used to originally identify the types of timing patterns, the proportion of cells for each timing pattern is independent of the decoding algorithm used in the NRP. The decoding algorithm used all neurons recorded (scaled and unscaled) and was the same across each NRP experimental condition (NRP-b, NRP-o, and NRP-TX) to minimize the influence of the decoder on the representation of timing patterns and, therefore, changes in the representation of timing patterns were most influenced by the loss of motor output and then the removal of afferent feedback (post transection).

Animals and behavioral training. Experiments were conducted on adult male Long-Evans rats (150-200 g body weight at training outset) housed separately in dedicated home cages and kept on an automatic $12 \mathrm{~h}$ light/dark cycle. One week before the outset of behavioral training, animals were gradually restricted access to water until they were allowed only maintenance levels $(100 \mathrm{ml} / \mathrm{kg} / \mathrm{d})$ to allow for reward-based training. All animal procedures were conducted in accordance with Drexel University Institutional Animal Care and Use Committee-approved protocols and followed established National Institutes of Health guidelines.

Rats were initially trained in the multiple-duration, skilled hindlimb press task (for review, see Knudsen et al., 2012), a variant of the press/no press task outlined in Manohar et al. (2012). Briefly, animals were trained in a custom-made Plexiglas chamber containing an inlet for water delivery and a moveable pedal connected to a press sensor pedal. An overhead LED array provided a cue that signaled the rat to perform the proper type of press. A correct press was defined as a press past a predefined threshold lasting the cued duration. All event times (cue onset times, reward times, press sensor, etc.) for each session were recorded and saved via a custom
LabVIEW (National Instruments) virtual instrument for off-line processing.

Surgical procedures. All surgical procedures and postoperative care for rats in this study have been described in detail previously (Knudsen et al., 2012; Manohar et al., 2012). All rats underwent at least two procedures (microelectrode implantation and complete mid-thoracic spinal cord injury); two animals underwent one additional EMG implantation procedure before spinal cord injury (SCI). All surgical procedures were performed under general anesthesia $\left(2-3 \%\right.$ isoflurane in $\mathrm{O}_{2}$ delivered via orotracheal intubation) and aseptic conditions. After training to proficiency, $4 \times 4$ arrays of $50 \mu \mathrm{m}$ Teflon-insulated, stainless steel microwires (MicroProbes for Life Sciences) were bilaterally implanted to the infragranular layers $(1.3-1.5 \mathrm{~mm})$ of the rat hindlimb representation within the sensorimotor cortex (Leergaard et al., 2004). In two animals, EMG recording electrodes were bilaterally implanted into the vastus lateralis and biceps femoris muscles of the hindlimbs and subcutaneously routed to a connector located at the animal's head. After completing pre-injury recording experiments (BC, NRP-b, NRP-o, and switch mode), rats received a complete T9/T10 spinal cord transection. Electrode placement and the completeness of each transection was assessed on $40-\mu \mathrm{m}$-thick coronal slices and longitudinal sections around the lesion site by Nisslmyelin staining for brain and spinal cord, respectively (Manohar et al., 2012).

Neuronal and EMG recordings. Before each recording session, rats were lightly anesthetized and headstages (Triangle Biosystems) were connected to implanted electrodes. Single neurons were discriminated by hand using a combined thresholding and real-time PCA analysis of waveform features. Neurons were re-discriminated before every recording session to ensure only single units were recorded. Neural signals were acquired $(40 \mathrm{kHz})$ with a neurophysiological recording system (Plexon) and synchronized to all event times (press sensor, cue times, reward times, etc.). Neural spike times were streamed to disk and saved for off-line analysis. EMG recordings were acquired at $1 \mathrm{kHz}$ synced to the neural clock and processed off-line.

$N R P$. The NRP is similar to BMI paradigms in that the single-trial neural activity is decoded and the animal is rewarded based on the accuracy of the decoding. As in our previous BMI paradigms (Chapin et al., 1999; Manohar et al., 2012), the NRP is used to disassociate the neural activity from the motor output and eventually replace it. All of the neurons, both scaled and unscaled, are used in the decoder (described below). This is because we cannot be sure of maintaining the identity of neurons (as scaled or unscaled) across days and, therefore, we do not know which cells are scaled and which are not before the experiment is completed on any given day. After each recording session (all control types), neural data were analyzed off-line using a combined PCA/independent components analysis (PCA/ICA) used previously by our lab. Details of the analysis can be found in Manohar et al. (2012). Briefly the PCA/ICA method reduces the dimensionality of the data from tens of neurons to a small number of principal components (maximum sources of variance in the population) using singular value decomposition, and then applies an extended Infomax ICA algorithm (Laubach et al., 1999) to the PCs accounting for $80-90 \%$ of the total variance, to maximize the statistical independence of the components, which make up several alternate reconstructions of the neural population activity. ICA component outputs have been shown to incorporate higher-order correlations between single neurons, which are lost when only examining covariance between neural firing rates as with PCA. The resulting ICA components can then be used, on-line, in subsequent recording sessions to generate weighted-sum reconstructions of the neural data or neural population functions (NPF) in real time. The single-trial NPF is used to classify the single-trial response as belonging to a short or long trial and, if classification matches the cue presented, the classifier triggers a water reward.

For the classification, on-line NPFs were used in conjunction with an on-line template-matching procedure, such that for a given trial, the real-time NPF was compared with off-line-generated NPF templates (trial-average NPFs) for three distinct events: background, in which the trial-average NPF was generated while animals were sitting quietly, and short and long press/trial, where the templates were generated from all correctly performed trials from the previous day (Fig. 2). This template- 
matching procedure was adapted from Foffani and Moxon (2004). For a given cue presentation, error functions associated with each template were generated for $1-1.5 \mathrm{~s}$ post cue. If at the end of this period the minimum error function corresponded to the requested cue, the rat would earn a water reward, otherwise the house lights were turned off and no rewards were given. In the example presented in Figure 2, the animal was presented with a "short" cue (flashing light); at the end of the classification period there was a minimum error between the short template and the NPF and thus, the animal received reward. ICA weights and templates were updated every day to maximize performance in the task. Under switch mode and NRP post-TX, the last weights and templates from NRP-o mode were used initially.

Analysis of climbing activity. Details of trial-average analyses of neurons can be found previously (Lebedev et al., 2008; Knudsen et al., 2012). Briefly, average firing-rate profiles (PETHs) for each neuron recorded were evaluated for the presence of stereotyped climbing activity. To address our first goal, analyses were done in a manner consistent with previous studies by using the start of press (for $\mathrm{BC}$ ) as the reference event and neural spike times were binned at $5 \mathrm{~ms}$ from $-1.5 \mathrm{~s}$ pre to $+3 \mathrm{~s}$ post reference event. Climbing activity was then assessed by a linear regression analysis of the smoothed ( $25 \mathrm{~ms}$ zero-phase distortion filter) average firing rates. Neurons with a linearity $\left(R^{2}\right)$ of at least 0.3 , a nonzero slope, and an overall change in firing rate, normalized by the SD of the entire peri-event window, of at least 2 were considered climbing. To consider neurons that presumably used temporally scaled activity to encode the two different intervals tested here, only cells that displayed climbing activity on both short and long trials were considered temporally scaled and used further.

Data recorded during the NRP tasks used the cue onset as the reference event to compare responses across tasks, because when the pedal was removed or the animal was transected identifying start of press was not possible. To determine whether the changing the reference event influenced the proportion of cells with different timing patterns, we compared the proportion of scaled neurons during $\mathrm{BC}$ using the start of press as the reference event to the proportion of scaled neurons using the time of cue onset as the reference event.

Evaluating temporal encoding. Each temporally scaled neuron's climbing parameters (i.e., slope of firing rate, change in firing rate, $R^{2}$, time to peak) were combined with overall measures of the response [(1) magnitude of the response: the firing rate in the unsmoothed average exceeding the average plus $3 \mathrm{SDs}$ of the background firing rate (from $t=-1.5$ to $t=$ $0)$; (2) peak response: the peak firing rate of the response; (3) peak latency: the time of peak firing rate] and input into a unsupervised combined PCA $/ k$-means analysis to determine whether common patterns of firing emerged. A cross-validation procedure was performed to determine the optimal number of clusters in the data (Figs. $1 D-F, 6 B$ ). For each control mode (e.g., BC, NRP-b, etc.), the data (response parameters) were randomized and divided evenly into 10 subsets. PCA/ $k$-means was performed on $9 / 10$ subsets as a training set then tested using the remaining subset. In this way, the fit of the clusters could be assessed. The number of clusters was tested from 2-11 within each control mode. For each mode, the optimal number (i.e., minimum cross-validation error) of clusters was five (four scaled, one unscaled; unscaled data not presented). Average response parameters for each resultant cluster were tabulated and combined with qualitative analyses of trial-average activity to classify each cluster as one of four scaling mechanisms. The number of neurons in each cluster was quantified and expressed as per animal measures (mean $\pm \mathrm{SD}$ ).

Statistics. All data are reported as mean values \pm SD unless otherwise specified. Statistical evaluations were performing using one-way ANOVA, one-way MANOVA, or nonparametric Wilcoxon tests. Kruskal-Wallis or Tukey post hoc tests were applied where appropriate. Due to a large number of statistical comparisons, false discovery rate analyses (Benjamini and Hochberg, 1995; Storey et al., 2004) were performed where appropriate though statistical interpretations did not change after these analyses. Statistical tests were considered significant at $p<0.05$, or associated adjustment of $p$ for multiple comparisons.

\section{Results}

Four patterns of scaled activity identified in primary motor cortex

After animals were well trained in a behavioral task to make either short $(t<1 \mathrm{~s})$ or long $(1.5<t<2.5 \mathrm{~s})$ duration presses with their hindlimb in response to different visual cues (Knudsen et al., 2012), we implanted them with microwire arrays in the hindlimb primary motor cortex (HLMC), retrained them to proficiency, and then recorded the activity from bilateral populations of single neurons while the animals performed the task (Fig. 1). First, the animals were rewarded for pressing the lever for the correct interval (BC) and the neural activity was saved for off-line analysis, similar to previous interval timing studies. We found a similar proportion of neurons engaged in temporal scaling (710 of 3077 responsive neurons; $23.1 \%$; Fig. $3 D$ ) compared with that identified in primate forelimb premotor cortex (Merchant et al., 2011; $34.4 \%)$. Moreover, the same four scaling patterns (slope, response magnitude, peak, or swing scaled; Fig. $1 D-F$; see experimental procedures for details) and only these scaling patterns were represented in similar proportions. These four patternsslope, response, peak, and swing scaled (Fig. $1 F$ )—may therefore be part of a distributed scaling mechanism (Buonomono and Karmarkar, 2002; Ivry and Spencer, 2004; Buhusi and Meck, 2005), which encodes for the different aspects of temporal estimation. In a timing context, each scaling pattern may be considered analogous to the relevant components of a stopwatch: remaining time in the estimate (slope scaled), timing state (on/ off; response scaled), elapsed time (peak scaled), and start and stop times (swing scaled), all of which are required for accurate estimation of the passage of time on short timescales. The majority of cells encoded remaining time through slope scaling (381 of 710 cells) such that the rate of change of the firing rate was proportional to the estimate. The second greatest representation encoded the state of timing through response scaling, which had sustained firing rates proportional to the length of the estimate (152 of 710). Third, fewer neurons overall encoded elapsed time through peak scaling that linearly increase firing at a constant rate throughout the estimate (98 of 710). Fourth, swing scaling encoded the start and stop times, characterized by a bimodal response around estimate end points (79 of 710). These data suggest that despite differences in task, species, and cortical area, neurons in the rat hindlimb motor cortex can adopt complex scaled patterns of activity during a movement timing task.

In our subsequent analyses of NRP neural activity, we changed the reference event from start of press to cue onset as animals no longer produced hindlimb movements. To verify that changing the reference event did not impact the classification of neurons, the distribution of scaled neurons during the $\mathrm{BC}$ task using the cue as the reference event was compared with the distribution when start of press was the reference and found a similar proportion of temporally scaled cells (651 of 3077 or $21.1 \%$ ). Using our clustering approach, the same four patterns were also found-slope (298 or 651 cells), response (161/651 cells), peak (88/651 cells), and swing (104/651 cells)_in similar proportions regardless of reference event (paired $t$ test for mean proportion of temporally scaled cells: $\left.t_{(3)}=0.5122, p=0.6439\right)$.

\section{Scaling patterns are not dependent on motor output in the primary motor cortex}

To determine whether these scaling patterns were a component of the motor program for timed movements, we transitioned rats $(n=8)$ to a neural reward context to gradually eliminate 
A

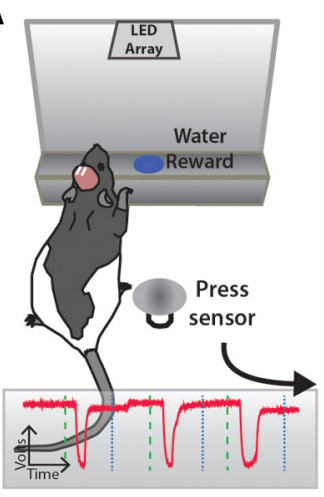

B
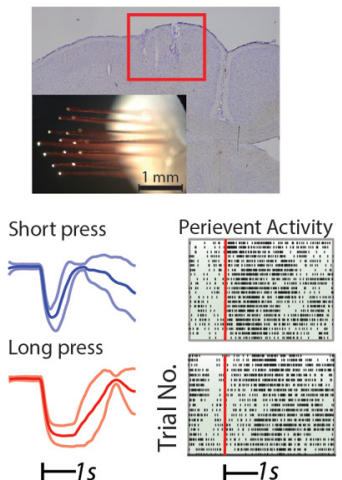

C

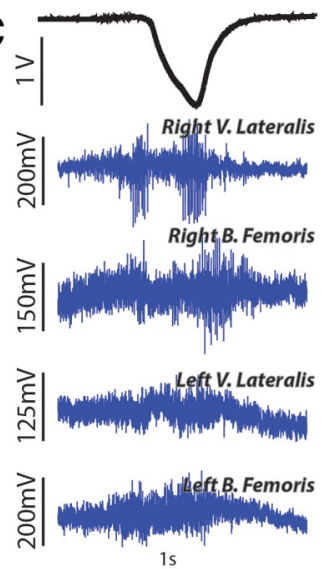

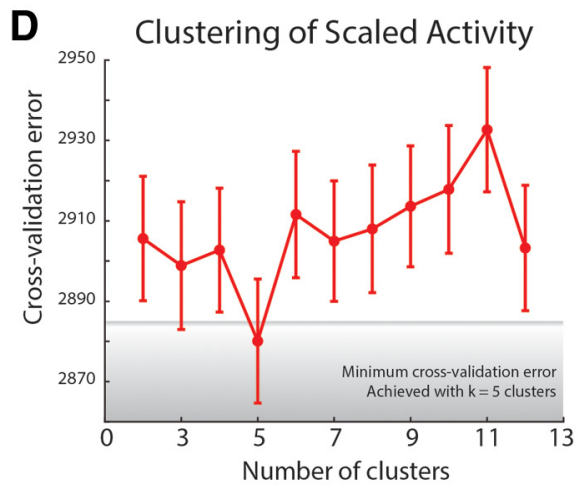

E Slope Scaled Response Scaled 15. Peak Scaled 10.

$\mathbf{F}$
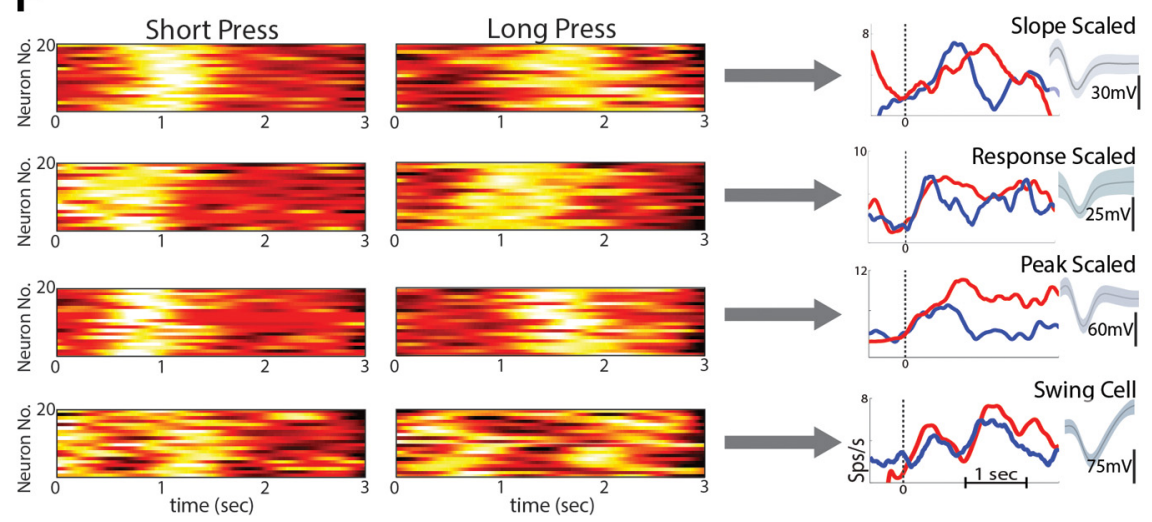

Figure 1. Scaled activity during the behavioral task. $\boldsymbol{A}$, Rats were initially trained to make short or long duration hindlimb presses onto a press sensor (inset: press sensor signal). $\boldsymbol{B}$, Microwire arrays were bilaterally implanted in the hindlimb sensorimotor cortex (top) and neural activity was recorded during behavior (bottom). C, Single-trial EMG recordings of hindlimb flexor and extensor activity during the behavioral task. D, Cross-validation analysis to cluster similar scaled responses from all scaled neurons. All response measures from each scaled neuron [response magnitude (RM), peak response (PR), time to peak ( $\left.t_{p}\right)$, change in firing rate $(\Delta \mathrm{FR})$, and slope $(\mathrm{b})]$ across short and long trials were input into a $k$-means clustering analysis to identify commonalities in average responses. The initial number of clusters was tested from 2 to 13 and $9 / 10$ ths of the data were used for clustering while the remaining 1/10th was used for testing. This procedure was then repeated 10 times (10-fold cross validation). Of all the initial settings for number of clusters, five clusters (i.e., $k=5$ ) resulted in the minimum cross-validation error (4 commonly scaled patterns, remaining cluster was unscaled). $\boldsymbol{E}$, Resultant average response measures of all scaled patterns (4) after clustering. $\boldsymbol{F}$, Combined with average responses, qualitative analysis of trial-average peri-event histograms ( 20 for each shown in pseudocolor) yielded slope, response, peak, and swing scaled neuron profiles. V., Vastus; B., biceps; k, parameter for number of clusters; Sps/s, spikes per second. ${ }^{* * *} p<0.001$.

hindlimb movements from the task using methods similar to our previous work (Manohar et al., 2012). First, using the data previously collected when the animals were rewarded for making a press of a sufficient duration in response to the appropriate cue given, we used a PSTH-based classification scheme (Foffani and Moxon, 2004; see Materials and Methods) to determine whether Swing Scaled

single trials could be classified as belonging to one of three classes: no press (which occurs in the precue window), short press, or long press (Fig. 2). Satisfied that offline we could specifically ( $\geq 80 \%$ correct) and selectively ( $<20 \%$ false positives) classify the different durations of press, we then tested the rats during experimental sessions when they were allowed to press the pedal but were rewarded only for neural responses that were correctly classified on-line depending on the type of cue delivered (NRP-behavior; NRP-b). After $\sim 6-7 \mathrm{~d}(6.5 \pm 1.3 \mathrm{~d}$; mean \pm SEM $)$ of testing, we removed the pedal so that rats could no longer make presses and instead were rewarded only for correct neural responses (NRP-only; NRP-o). There were no significant decreases in task performance when we transitioned rats from behavior to NRP control (Fig. $3 A$; one-way repeated-measures ANOVA for mean per rat performance by mode, $F_{(1.894,28.41)}=$ $1.294, p=0.2886$ ). In two rats, we simultaneously recorded EMG signals from bilateral hindlimb knee extensor and flexor muscles (vastus lateralis; biceps femoris, respectively) to verify that animals were not simply performing isometric muscle contractions during NRP-o (Figs. $1 C$; behavior EMG; $3 C$; BC vs NRP-o EMG).

Analysis of trial-averaged activity revealed similar proportions of neurons that were temporally scaled under both NRP-b and NRP-o conditions (Fig. 3D; NRP-b: 542/2056 cells; NRP-o: 520/1936; one-way ANOVA for proportion scaled per recording session: $F_{(2,166)}=0.5767$, $p=0.563)$. Therefore, the on-line decoding did not influence cells to behave in a more temporally scaled manner. Moreover, we identified the same four scaling patterns and only these four patterns (Fig. $3 B$ ). However, as rats learned to eliminate hindlimb movements from the task, the distribution of the scaling patterns across the neurons changed (Fig. 3E; one-way MANOVA: $\left.F_{(8,314)}=44.797, p<0.0001\right)$. Overall the number of neurons using slope scaling decreased as training moved from behavioral to NRP-b to NRP-o (mean difference: 18.85\%; $p<0.0001$ ). Concomitantly, there was an increase in those using response scaling $(p<0.0001)$, with no change in the number of cells using peak or swing scaling. These data suggest that these neural scaling patterns represent relevant components of a brainwide distributed timing network that encodes temporal intervals yet, importantly, these components, even in the motor cortex, are not dependent on movement output. To investigate the nature of the changes further, we next tested rats under the behavioral and NRP-o tasks within single experimental sessions to determine 


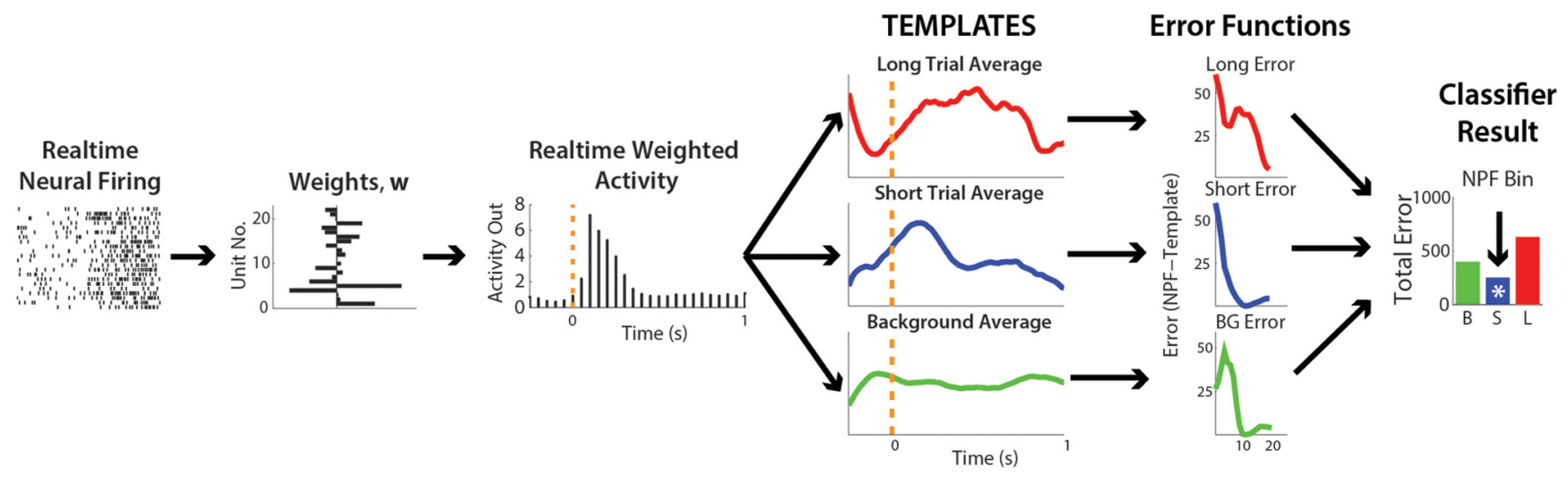

Figure 2. Schematic illustration of online neural classifier. Neural spike times are acquired and weighted in real time to generate the weight population activity. On the onset of a trial, ongoing population activity is compared bin by bin to templates derived from the previous days' experiment. At the end of the trial, the minimum error between the population activity and the template was considered the classification result: if the cued trial matched the predicted template, the rat was given a water reward. * indicates the trial was classified as short because the error was the smallest.

whether the changing representation reflected permanent changes in cortical strategies for encoding temporal estimates.

\section{Changes to the scaling mechanism are reversible}

In the above experiments, we identified changes in the distribution of scaling patterns across recorded neurons when the hindlimbs were decoupled from the task and demonstrated changes in the encoding despite the fact that there was no overall change in the numbers of neurons producing scaled behavior. To determine whether these were permanent changes in the network representation of the temporal intervals or if they were context dependent changes, we retested three rats in a series of switch experiments that alternated blocks (each block $=$ approximately one-third of total rewards per session; $\sim 3-4 \mathrm{ml}$ of water) of behavioral and NRP-o trials within single experimental sessions (Fig. 4). Similar to experiments in monkeys (Ganguly et al., 2011), rats were able to perform both tasks equally well (Fig. $4 B-E$; Kruskal-Wallis test of performance rate; behavior: $K_{(4,24)}=2.609, p=0.4559$; BMI-o: $K_{(3,28)}=$ $2.129, p=0.8394$ ), so we combined similar trials (switch BC or NRP-o) across blocks regardless of their sequence ( $n=3$ rats; $16 \mathrm{BC}, 16 \mathrm{NRP}$-o blocks).

First, as we previously noted for different tasks (behavior vs NRP), the proportion of temporally scaled neurons remained consistent across conditions (Fig. 4F; behavior vs switch behavior and NRP-o vs switch NRP-o; $\left.F_{(4,196)}=0.3049, p=0.8745\right)$. Importantly, the distribution of scaling patterns was consistent with the distribution in preswitch experiments (Fig. $4 G$ ), suggesting that changes in the encoding of scaled activity are contextually dependent and reversible. Remaining time, encoded through slope scaling, was used by the majority of scaled neurons during BC, whether pre-NRP or during switch experiments (slope: 54/ 154 neurons; response: 37/154; peak: 22/154; swing: 41/154). Similarly, timing state, encoded through response scaling, was the predominant pattern in the absence of hindlimb movements during NRP-o, both during NRP training and switch experiments (Fig. $4 G$; slope: $24 / 170$ neurons; response: $86 / 170$; peak: 27/170; swing: 34/170). In fact, we identified individual neurons that changed encoding from slope to response scaled when the task switched from behavior to NRP-o, and returned to slope scaling when the task switched back to the behavioral task (Fig. 5). EMG recorded during this experiment verified that the rat was not engaging its hindlimb during NRP-o trials. Since the same on-line neural decoder was used across both tasks (NRP-b and
NRP-o), it is unlikely that the neural decoder itself was responsible for the shift in the proportions of scaled types. These experiments extend our understanding that HLMC neurons alter their encoding depending on the task context (Roux et al., 2003; Coull and Nobre, 2008; Knudsen et al., 2012) by changing the distribution of scaling patterns for encoding. Yet the continued emergence of all four scaling patterns while rats performed the movement-decoupled task supports our proposal that all four scaling patterns are necessary for temporal estimation, which we show is independent of motor output in the in-tact rat.

\section{Complete SCI transiently disrupts scaling mechanism}

Until now we showed that the encoding of temporal estimates is altered when hindlimb movements are removed from the task through a real-time NRP in healthy adult rats, though these alterations were as follows: (1) still relevant to temporal estimation in the absence of movement and (2) reversible within single recording sessions. To test the effects of eliminating afferent feedback, we asked whether encoding of temporal estimates continued following a complete mid-thoracic (T9/T10) spinal cord transection that decouples the hindlimb cortex from its motor targets and sensory inputs. After recovery from injury (7 d), the neuronal activity was not initially sufficient to trigger a reward from the NRP $(n=4)$. Presumably, this is due to the direct damage to many of these cells whose axons are severed during the transection procedure. However, $10-13 \mathrm{~d}(11.5 \pm 3.2 \mathrm{~d} ;<21 \mathrm{~d}$ post-TX) of training in the task were required before the neural activity reorganized to successfully ( $>70 \%$ success rate) perform the task (Fig. 6A), consistent with our previous work (Manohar et al., 2012). This is similar to the early work of Olds (1965) and Fetz (1969) showing neurons can be trained to modify their activity for a reward (for review, seeGanguly and Carmena, 2009; Manohar et al., 2012; Ganguly et al., 2011 for more recent studies in BMIs). However, after SCI there is an upregulation of proteins associated with plasticity (Endo et al., 2007; Graziano et al., 2013) and, therefore, this training is occurring in a more plastic state, likely supporting the functional reorganization.

Based on our results from pre-injury, we hypothesized that good performance in the task was correlated to task-related neural activity and by extension-scaled activity, so we assessed temporal scaling only on days when rats performed well. No new scaling patterns emerged from the scaling subpopulation (Fig. $6 B, C)$ although fewer neurons were temporally scaled overall 
A
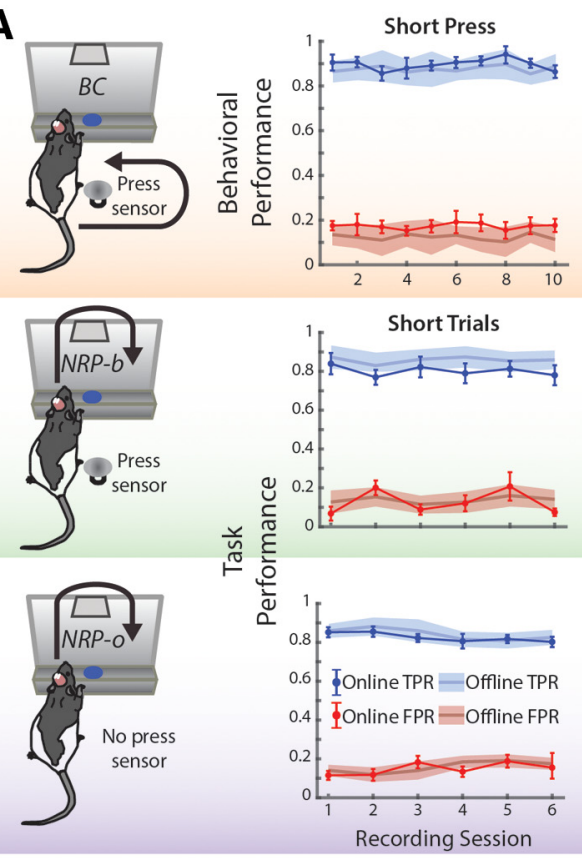

D
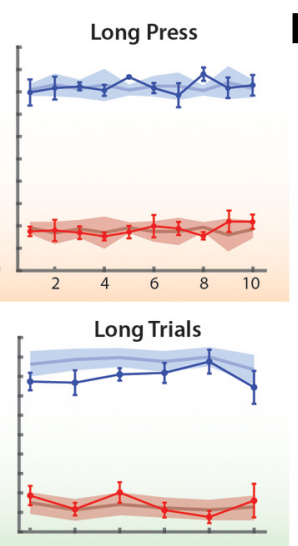

B

NRP Behavior
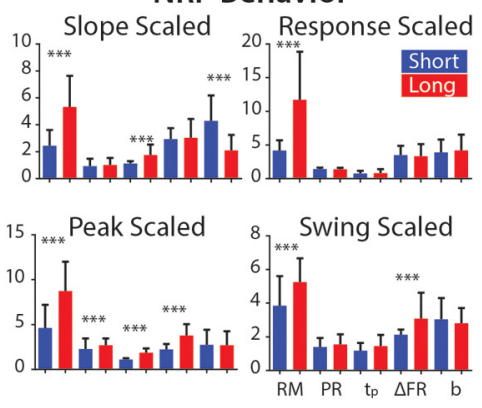

\section{NRP Only}
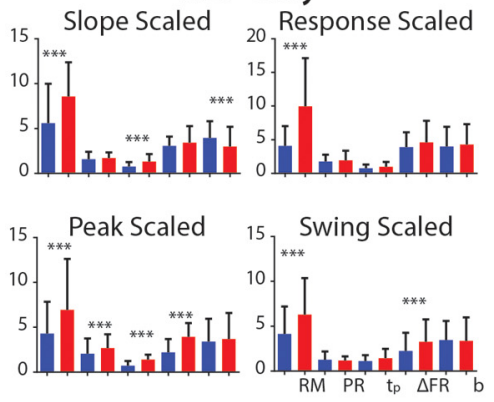

C

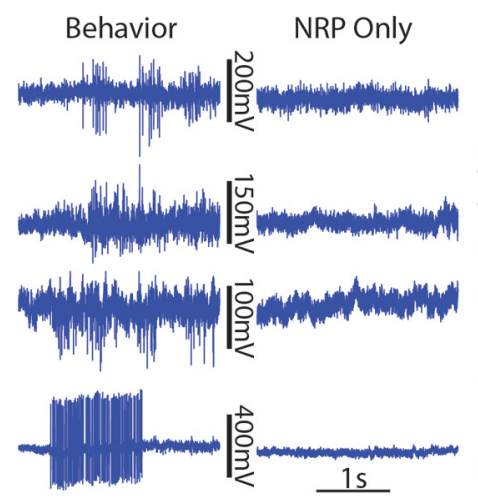

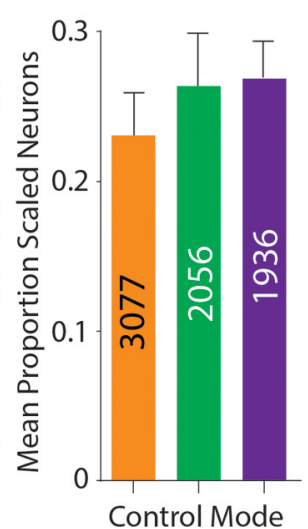

E

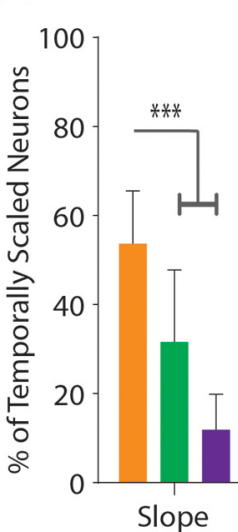

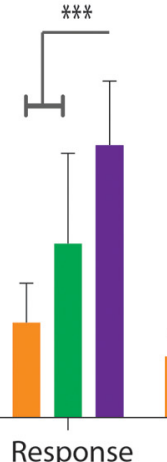

Scaling Mechanism

Figure 3. Task performance and temporal encoding during the NRP task. $\boldsymbol{A}$, Overall performance in the task did not change from behavior to the movement-dissociated NRP task (NRP-0). $\boldsymbol{B}$, Average measures from each scaled population determined from $k$-means analysis during NRP-b and NRP-0. A characteristic "fingerprint" for each scaled pattern is conserved across mode. $C$, Single-trial EMG during the BMI-o task; there was minimal EMG activation during performance of the NRP- 0 task compared with the behavioural task (BC) for the same animal; targeted muscles are as defined in Figure 1; however, EMG from a different animal (NRC.024) with greater SNR on left biceps femoris is shown here. $\boldsymbol{D}$, No effect of task on the mean (+SEM) proportion of the total population of task-related neurons that displayed scaled activity. $\boldsymbol{E}$, There was an effect of task on the distribution of scaled neurons: during the behavioral task, the majority of scaled neurons were slope scaled, while in the NRP-0 task, the majority of neurons were response scaled. TPR, True positive rate; FPR, false postivie rate. ${ }^{* * *} p<0.001$.

(Fig. $6 D$; one-way ANOVA for proportion neurons scaled: $F_{(3,187)}=$ 15.3, $p<0.0001)$ compared with pre-TX. As with the pre-injury movement-dissociated NRP task, the majority of scaled neurons encoded timing state using response scaling (77/187 neurons), falling from pre-TX BMI-o [mean difference (m.d.) $=-19.9 \%$, $p<0.0001$ ] yet increased compared with pre-TX behavior (m.d. $=$ $19.8 \%, p<0.0001$ ). In a similar manner, the proportion of neurons encoding remaining time using slope scaling (42/187) was greater than pre-TX NRP (m.d. $=10.8 \%, p<0.0001$ ) but less than pre-TX behavior (m.d. $=-31 \%, p<0.0001$ ). Finally, there were also significant increases in the proportion of neurons encoding both elapsed time (peak scaled, $40 / 187$; behavior m.d. $=7.4 \%$, $p<0.0001$; NRP-o m.d. $=6.4 \%, p<0.0001)$ and start and stop times (swing scaled, 28/187) relative to pre-TX tasks (behavior m.d. $=3.8 \%, p<0.001$; NRP-o m.d. $=2.8 \%, p<0.01$ ). This resulted in a more equal distribution of the four scaling patterns after a complete spinal transection from a subset of neurons that relearn the temporal estimations using all the components of the scaling mechanism to restore the neural stopwatch. Therefore, not only is motor output not necessary for temporal scaling of neuronal patterns of activity, but afferent feedback is not required either.

\section{Discussion}

In this study, we investigated the effects of both movement dissociation and the removal of afferent feedback on the hindlimb motor cortex representation of interval time. We demonstrate that the encoding of temporal intervals is conserved in the absence of movement and after a complete spinal transection. This encoding is consistent with climbing activity-based encoding mechanisms identified in nonhuman primates across a wide range of brain regions and tasks. 
A

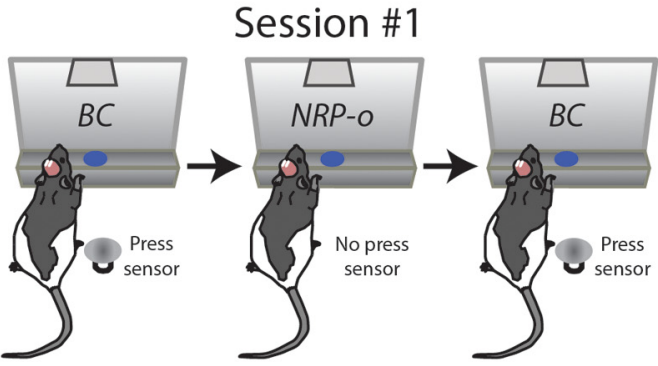

\section{Session \#2}

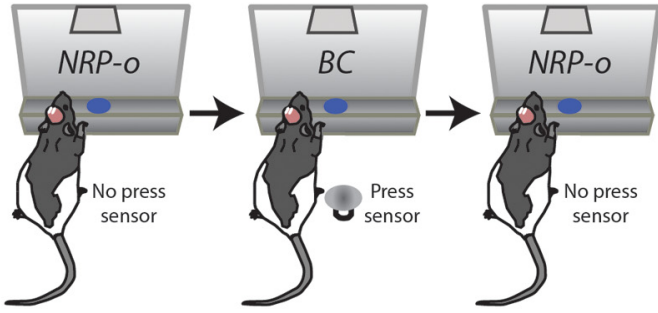

B

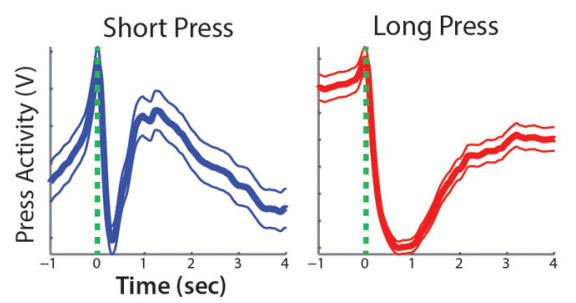

D

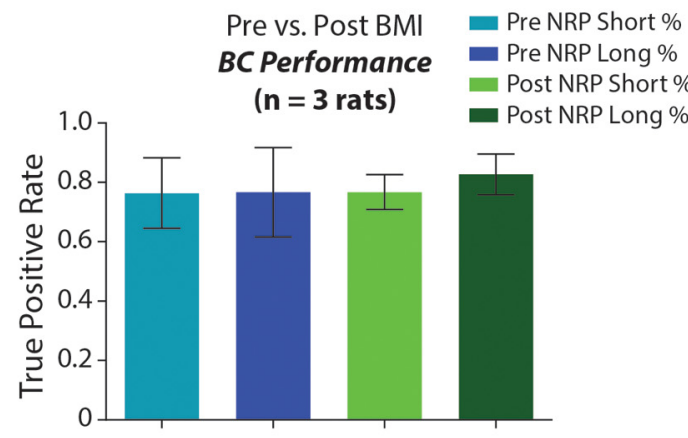

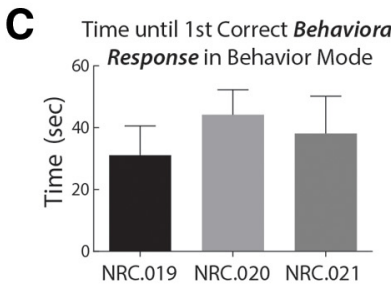
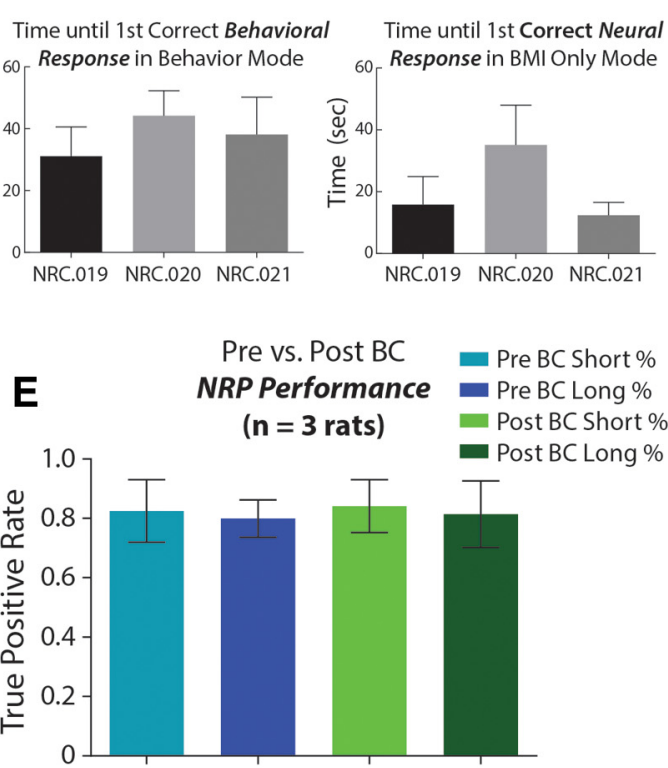

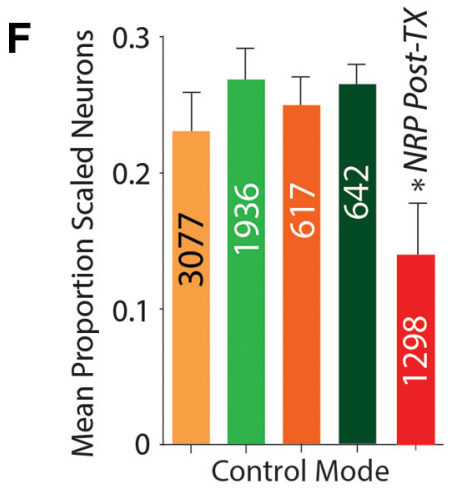

$\mathbf{G}$

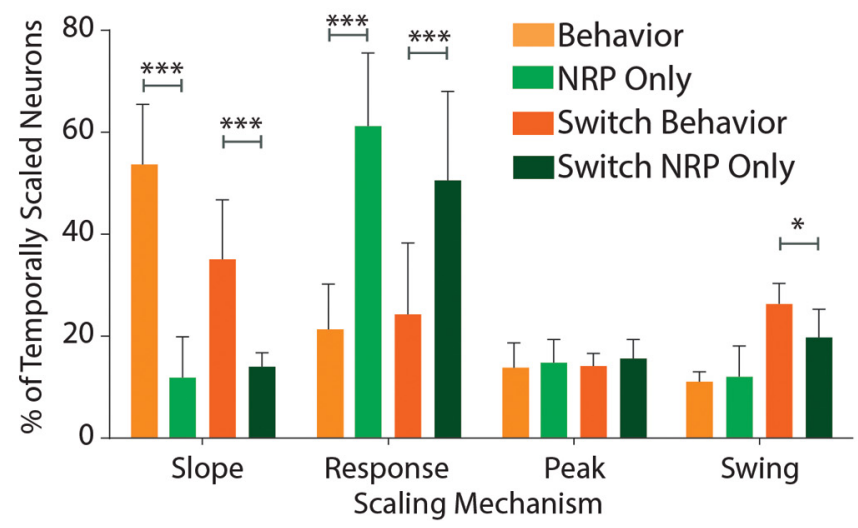

Figure 4. Behavioral performance and temporal encoding during switch experiments. $A$, For switch experiments, rats were tested in alternating blocks of $B C$ (behavioral task) and the no-movement NRP task (NRP-0) in both sessions \#1 and \#2. B, Overall average hindlimb press profiles ( \pm SD); despite being tested under NRP modes for several weeks preceding switch mode. C, In fact, rats were able to adapt and perform well in the hindlimb timing task in a short amount of time. Left, Between $30-50$ s or 5-10 trials before first correct behavioral response. Right, Similarly rats were able to perform well under NRP control (15-35 s or 2-8 trials) after performing the hindlimb timing task. $\boldsymbol{D}$, There was no effect of a BC block either preceding or following an NRP-o block on overall BC task performance for short or long estimates. $\boldsymbol{E}$, No effect of an NRP-o block preceding or following a BC block on NRP-o task performance. $\boldsymbol{F}$, The proportion of scaled neurons did not change pre-TX regardless of the mode. However, post-TX there was a significant decrease in the proportion of scaled neurons. $\mathbf{G}$, Moreover, difference between behavior mode and NRP for the different scaling mechanisms was similar to difference between Switch Behavior and Switch NRP Only. ${ }^{*} p<0.05,{ }^{* * *} p<0.001$.

There are, however, several other proposed mechanisms for interval timing in addition to climbing activity. For example, Merchant et al. (2013a) showed that neurons in dorsal premotor cortex during a timing task are "tuned" to a preferred temporal interval, a phenomenon that was also found in the putamen of behaving primates (Bartolo et al., 2014). In the current study, although we only used two durations, we also identified several neurons $(\sim 10 \%)$ that were scaled only for one of the two durations, and thus we cannot discount the interval tuning hypothesis. A second example using EEG activity showed that changes in the amplitude of the evoked potential to an auditory stimulus demarking the end of an interval was a better measure of the 

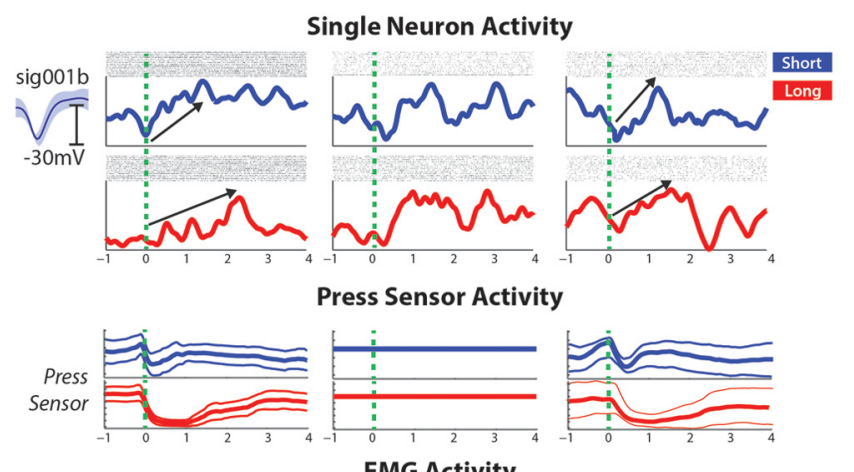

EMG Activity

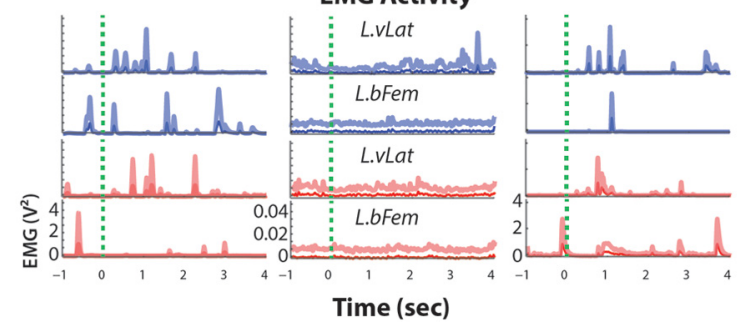

Figure 5. Switch mode single-cell example. Single slope-scaled neuron during switch $B C$ (left column; along with trial-average press sensor and EMG data), switched to response scaling during switch NRP-o (middle column) before returning to slope scaling after the final switch (right column). L.vLat, Left vastus lateralis; L.bFem, left biceps femoris.

interval than the contingent negative variation (CNV) of the EEG activity, an index of the underlying scaled neural activity. We conclude that $\mathrm{CNV}$, and thus climbing neural activity, is a reflection of more generalized anticipatory activity. Contrary to this, we previously showed that the presence of scaled neural activity significantly improved our ability to predict press duration in a timed movement task (Knudsen et al., 2012). Within the context of the present results, it is likely that slope-scaled activity (the single-neuron reflection of the $\mathrm{CNV}$ ) is a generalized anticipatory signal that demarks the remaining time until some behaviorally relevant event, in this case an upcoming movement. However, we observed a de-emphasis on these patterns when the movement was decoupled from the task, suggesting this scaling pattern is prevalent when movement is timed. Furthermore, slope scaling was but one of four distinct scaled patterns of activity, thus it is likely that each pattern individually reflects some generalized process. For example, sustained neural activity during delay periods (response-scaled activity) is thought to be a reflection of task-related working memory (Goldman-Rakic, 1995; Lewis and Miall, 2003, 2006). Similarly, increased activation at the terminal ends of an estimate (swing-scaled activity) could be preparatory in nature; however, these same terminal activations are thought to contribute to temporal calculations (Kononowicz and van Rijn, 2014). Thus, it is likely each of the generalized activity patterns combine to form the basis of a robust timing representation.

Importantly, the temporally scaled activity that is relearned following complete spinal transection suggests a potential therapy for the restoration of volitional control of locomotion in patients suffering from severe spinal injuries. Despite recent experiments demonstrating restoration of stereotypic locomotion through electrically and/or pharmacologically induced activation of intact spinal circuits below the lesion (Antri et al., 2005; Courtine et al., 2009), the prospect of simply walking down a path where objects interfere with this rhythmic, stereotypic locomotion would be daunting for someone with severe spinal cord injury. A plan to coordinate the timing of modifications to the step cycle is necessary to successfully traverse obstacles in such an environment. In healthy animals, central pattern generators (Delcomyn, 1980; Grillner, 2006) in the lumbosacral spinal cord (Kiehn, 2006; Hägglund et al., 2013) are activated by supraspinal circuits (Jordan et al., 2008; Hägglund et al., 2010) and provide the rhythmic output that drives the step cycle. Information about the step cycle is encoded in the motor cortex (Fitzsimmons et al., 2009; Song et al., 2009) although this information is not strictly required for stereotypic locomotion, even after spinal cord injury (Ichiyama et al., 2008). When an obstacle is encountered; however, cortically mediated signals controlling the desired timing and magnitude of modifications to the step cycle are necessary to restore open field locomotion (Widajewicz et al., 1994). In our study the timed hindlimb press acts as a surrogate for these modifications to a stereotypic step cycle. Here we demonstrate that the encoding of temporal estimates are relearned following injury, making this information available within areas of the brain commonly used as a source of BMI to control intact spinal circuits below the level of the lesion and re-enable navigation in the open field.

The fact that these four patterns of activity are reestablished after SCI further supports the idea that these patterns are critical for the encoding of interval time. The relationship between these patterns of activity and timed movements are analogous to a stopwatch-the remaining time (slope scaled), timing state (response scaled), elapsed time (peak scaled), and interval endpoints (swing scaled)and are in agreement with previous studies of movementrelated interval timing (Roux et al., 2003; Renoult et al., 2006; Lebedev et al., 2008; Merchant et al., 2011). The majority of those studies used timed behavioral output as the correlate of the internalized time metric. However, by introducing the NRP task, we were able to disassociate the movement from the internal representation of time. The limited influence of the task context on these patterns is likely due to the fact that the temporally scaled cells represent a small proportion of cells used to control the water reward $(\sim 20-30 \%)$.

Nevertheless, there were significant changes in the encoding mechanism when the NRP was substituted for motor output. These changes could be due solely to the cessation of motor output; however, it is possible that changes in single-neuron activity are due to learning the NRP task. Several studies have demonstrated that M1 neurons in the monkey undergo changes in tuning when directly (Ganguly and Carmena, 2009; Manohar et al., 2012) or indirectly (Ganguly et al., 2011) involved in BMI control, and these changes in tuning can directly reflect the type of decoder used (Lebedev et al., 2005). In the current study, during NRP-o control, rats no longer made hindlimb movements but were still engaged in estimating temporal intervals and thus the need for estimating the remaining time (slope scaled) was reduced, while the encoding of the general estimate (state-response scaled) was of greater importance. On the one hand, this increase in the number of neurons using response-scaled patterns to represent the interval may be due to our choice of decoder. However, response-scaled patterns of activity have been implicated as mechanisms for short-term storage and the integration of sensory (Komura et al., 2001; Brody et al., 2003) or motor (Kojima et al., 1996) information. Moreover, during a working memory task, Baeg et al. (2003) reported alterations in sustained firing patterns during learning processes. The increase in response-scaled activity during NRP may therefore be a reflection of the interval being either recalled (for estimation of an interval) or stored (during learning) during perfor- 
A Online Performance
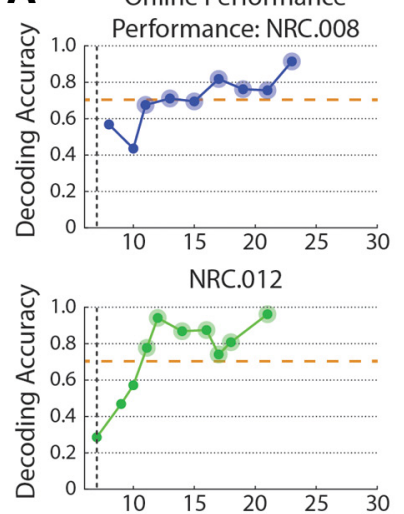

C
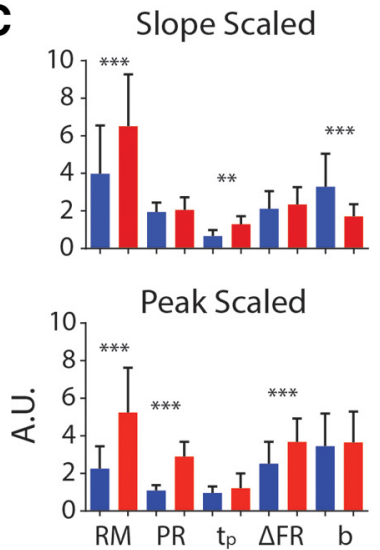
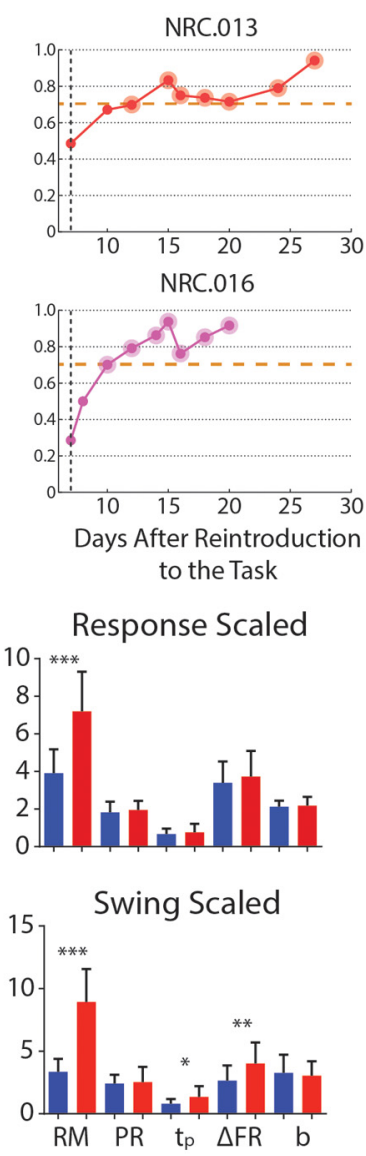

B
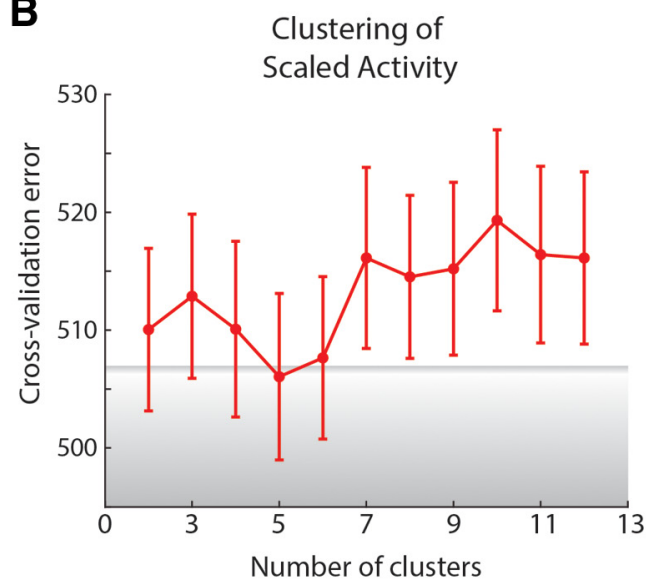

D

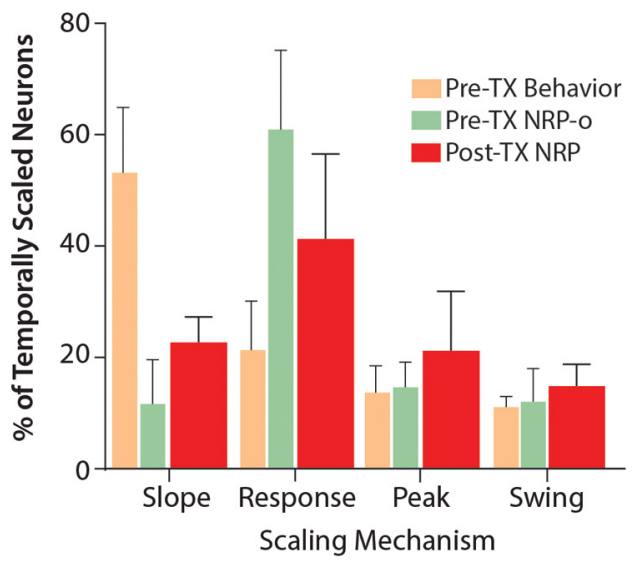

Figure 6. Post-spinal TX NRP task performance and temporal scaling. $A$, Rats did not perform well in the task until $\sim 10-13 \mathrm{~d}$ post reintroduction to the task after recovery from injury $(\sim 21 \mathrm{~d}$ post injury), so we evaluated neural activity during days with good task performance (larger markers above dashed line at accuracy $=0.7) . \boldsymbol{B}, \boldsymbol{C}$, Analysis of neural activity on good days revealed the same four scaled patterns based on clustering cross-validation and resultant average neural responses. $D$, Response-scaled activity comprised the majority of scaled neural responses $(F=149.91, p<0.0001)$; however, slope $(F=271.1, p<0.0001)$, peak $(F=11.26, p<0.001)$, and swing $(F=5.834, p=0.004)$ were all increased compared with the pre-injury NRP-task.

mance of the task in the absence of any downstream transmission of the motor program.

The changes we observed were rapidly reversible within a single experimental session suggesting these changes in encoding are context dependent. Ganguly et al. (2011) alternated epochs of behavioral (manual) and NRP (brain) control within single experiments and showed that neurons "switched" their encoding depending on the task demands within a small number of repeated trials. In our study, the consistent identification of these four scaled patterns suggests to us that, despite changes in their distribution, these patterns subserve the timing abilities of the cortex and are largely unaffected by context or the loss of afferent feedback.

This is important because the repertoire of animal behavior thought to be enabled by interval timing extends beyond timing of movements. These non-motor functions include cognitive processes such as working memory (Goldman-Rakic, 1995; Baeg et al., 2003; Brody et al., 2003), decision making (Kim and Shadlen, 1999; Mazurek et al., 2003; Kalenscher and Pennartz, 2008; Sugrue et al., 2005; Kim et al., 2013), visual perceptions such as collision avoidance (Hatsopoulos et al., 1995; Rind and Simmons, 1997, Rind and Simmons, 1999; Sun and Frost, 1998), and visual attention (Esterman and Yantis, 2010; Salvioni et al., 2013). Therefore, despite the fact that the origin of these locally encoded estimates remains unclear, the consistency of this neural activity with that observed in other brain regions, different animal species, and across a broad range of tasks, both motor and non-motor, suggests that some abstracted form of the timing task is cognitively being performed in the motor cortex. This is further supported by the fact that the re-emergence of all four scaling patterns after complete spinal transection coincides with improvement in performance. Therefore, the hindlimb region of the motor cortex participates in cognitive tasks, such as the encoding of temporal intervals, even when the task is completely disassociated from motor output.

The consistency of temporal scaling across species, task, and brain regions and its re-emergence after spinal transection suggests that temporal scaling patterns subserve the mechanism used to accurately encode the estimate of temporal intervals independent of context. Furthermore, our study suggests that these patterns extend to interval timing on the second timescales (Grondin, 2012; Rammsayer and Troche, 2014). However, it must be pointed out that in this study, we only trained rats to discriminate between two intervals, compared with the multiple intervals tested in several other studies (Merchant et al., 2011, 2013a). The ubiquity of these patterns throughout the brain and their participation across a wide range of contexts, including the novel neural reward paradigm 
demonstrated here, gives insight into the flexibility of the proposed brain-wide distributed timing network (Buonomono and Karmarkar, 2002; Ivry and Spencer, 2004; Buhusi and Meck, 2005).

\section{References}

Antri M, Barthe, JY, Mouffle C, Orsal D (2005) Long-lasting recovery of locomotor function in chronic spinal rat following chronic combined pharmacological stimulation of serotonergic receptors with 8-OHDPAT and quipazine. Neurosci Lett 384:162-167. CrossRef Medline

Baeg EH, Kim YB, Huh K, Mook-Jung I, Kim HT, Jung MW (2003) Dynamics of population code for working memory in the prefrontal cortex. Neuron 40:177-188. CrossRef Medline

Bard C, Paillard J, Lajoie Y, Fleury M, Teasdale N, Forget R, Lamarre Y (1992) Role of afferent information in the timing of motor commands: a comparative study with a deafferented patient. Neuropsychologia 30: 201-206. CrossRef Medline

Bartolo R, Prado L, Merchant H (2014) Information processing in the primate basal ganglia during sensory-guided and internally driven rhythmic tapping. J Neurosci 34:3910-3923. CrossRef Medline

Benjamini Y, Hochberg Y (1995) Controlling the false discovery rate: a practical and powerful approach to multiple testing. J R Stat Soc B 57: 289-300.

Billon M, Semjen A, Gauthier G (1996) The role of sensory information in the production of periodic finger-tapping sequences. Exp Brain Res 110: 117-130. CrossRef Medline

Brody CD, Romo R, Kepecs A (2003) Basic mechanisms for graded persistent activity: discrete attractors, continuous attractors, and dynamic representations. Curr Opin Neurobiol 13:204-211. CrossRef Medline

Buhusi CV, Meck WH (2005) What makes us tick? Functional and neural mechanisms of interval timing. Nat Rev Neurosci 6:755-765. CrossRef Medline

Buonomano DV, Karmarkar UR (2002) How do we tell time? Neuroscientist 8:42-51. CrossRef Medline

Chapin JK, Moxon KA, Markowitz RS, Nicolelis MA (1999) Real-time control of a robot arm using simultaneously recorded neurons in the motor cortex. Nat Neurosci 2:644-670. CrossRef Medline

Coull J, Nobre A (2008) Dissociating explicit timing from temporal expectation with fMRI. Curr Opin Neurobiol 18:137-144. CrossRef Medline

Courtine G, Gerasimenko Y, van den Brand R, Yew A, Musienko P, Zhong H, Song B, Ao Y, Ichiyama RM, Lavrov I, Roy RR, Sofroniew MV, Edgerton VR (2009) Transformation of nonfunctional spinal circuits into functional states after the loss of brain input. Nat Neurosci 12:1333-1342. CrossRef Medline

Crammond DJ, Kalaska JF (2000) Prior information in motor and premotor cortex: activity during the delay period and effect on pre-movement activity. J Neurophysiol 84:986-1005. Medline

Delcomyn F (1980) Neural basis of rhythmic behavior in animals. Science 210:492-498. CrossRef Medline

Endo T, Spenger C, Tominaga T, Brené S, Olson L (2007) Cortical sensory map rearrangement after spinal cord injury: fMRI responses linked to Nogo signalling. Brain 130:2951-2961. CrossRef Medline

Esterman M, Yantis S (2010) Perceptual expectation evokes categoryselective cortical activity. Cereb Cortex 20:1245-1253. CrossRef Medline

Fetz EE (1969) Operant conditioning of cortical unit activity. Science 163: 955-958. CrossRef Medline

Fitzsimmons NA, Lebedev MA, Peikon ID, Nicolelis MA (2009) Extracting kinematic parameters for monkey bipedal walking from cortical neuronal ensemble activity. Front Integr Neurosci 3:3. CrossRef Medline

Foffani G, Moxon KA (2004) PSTH-based classification of sensory stimuli using ensembles of single neurons. J Neurosci Methods 135:107-120. CrossRef Medline

Ganguly K, Dimitrov DF, Wallis JD, Carmena JM (2011) Reversible largescale modification of cortical networks during neuroprosthetic control. Nat Neurosci 14:662-667. CrossRef Medline

Ganguly K, Carmena JM (2009) Emergence of a stable cortical map for neuroprosthetic control. PLoS Biol 7: e1000153. CrossRef Medline

Genovesio A, Tsujimoto S, Wise SP (2009) Feature-and order-based timing representations in the frontal cortex. Neuron 63:254-266. CrossRef Medline

Goldman-Rakic PS (1995) Cellular basis of working memory. Neuron 14: 477-485. CrossRef Medline
Graziano A, Foffani G, Knudsen EB, Shumsky J, Moxon KA (2013) Passive exercise of the hindlimbs after complete thoracic transection of the spinal cord promotes cortical reorganization. PLoS One 8:e54350. CrossRef Medline

Grillner S (2006) Biological pattern generation: the cellular and computational logic of networks in motion. Neuron 52:751-766. CrossRef Medline

Grondin S (2012) Violation of the scalar property for time perception between 1 and 2 seconds: evidence from interval discrimination, reproduction, and categorization. J Exp Psychol Hum Percept Perform 38:880 890. CrossRef Medline

Hägglund M, Borgius L, Dougherty KJ, Kiehn O (2010) Activation of groups of excitatory neurons in the mammalian spinal cord or hindbrain evokes locomotion. Nat Neurosci 13:246-252. CrossRef Medline

Hägglund M, Dougherty KJ, Borgius L, Itohara S, Iwasato T, Kiehn O (2013) Optogenetic dissection reveals multiple rhythmogenic modules underlying locomotion. Proc Nat Acad Sci USA 110:11589-11594. CrossRef Medline

Hatsopoulos N, Gabbiani F, Laurent G (1995) Elementary computation of object approach by a wide-field visual neuron. Science 270:1000-1003 . CrossRef Medline

Ichiyama RM, Courtine G, Gerasimenko YP, Yang GJ, van den Brand R, Lavrov IA, Zhong H, Roy RR, Edgerton VR (2008) Step training reinforces specific spinal locomotor circuitry in adult spinal rats. J Neurosci 28:7370-7375. CrossRef Medline

Isomura Y, Harukuni R, Takekawa T, Aizawa H, Fukai T (2009) Microcircuitry coordination of cortical motor information in self-initiation of voluntary movements. Nat Neurosci 12:1586-1593. CrossRef Medline

Ivry RB, Spencer RM (2004) The neural representation of time. Curr Opin Neurobiol 14:225-232. CrossRef Medline

Janssen P, Shadlen MN (2005) A representation of the hazard rate of elapsed time in macaque area LIP. Nat Neurosci 8:234-241. CrossRef Medline

Jordan LM, Liu J, Hedlund PB, Akay T, Pearson KG (2008) Descending command systems for the initiation of locomotion in mammals. Brain Res Rev 57:183-191. CrossRef Medline

Kalenscher T, Pennartz CM (2008) Is a bird in the hand worth two in the future? The neuroeconomics of intertemporal decision-making. Prog Neurobiol 84:284-315. CrossRef Medline

Kiehn O (2006) Locomotor circuits in the mammalian spinal cord. Annu Rev Neurosci 29:279-306. CrossRef Medline

Kim JN, Shadlen MN (1999) Neural correlates of a decision in the dorsolateral prefrontal cortex of the macaque. Nat Neurosci 2:176-185. CrossRef Medline

Kim J, Ghim JW, Lee JH, Jung MW (2013) Neural correlates of interval timing in rodent prefrontal cortex. J Neurosci 33:13834-13847. CrossRef Medline

Knudsen EB, Flint RD, Moxon KA (2012) Encoding of interval time in the rat hindlimb sensorimotor cortex. Front Syst Neurosci 6:67. CrossRef Medline

Kojima J, Matsumura M, Togawa M, Hikosaka O (1996) Tonic activity during visuo-oculomotor behavior in the monkey superior colliculus. Neurosci Res 26:17-28. CrossRef Medline

Komura Y, Tamura R, Uwano T, Nishijo H, Kaga K, Ono T (2001) Retrospective and prospective coding for predicted reward in the sensory thalamus. Nature 412:546-549. CrossRef Medline

Kononowicz TW, van Rijn H (2014) Decoupling interval timing and climbing neural activity: a dissociation between CNV and N1P2 amplitudes. J Neurosci 34:2931-2939. CrossRef Medline

Laubach M, Shuler M, Nicolelis MA (1999) Independent component analysis for quantifying neuronal ensemble interactions. J Neurosci Methods 94:141-154. CrossRef Medline

Lebedev MA, Messinger A, Kralik JD, Wise SP (2004) Representation of attended versus remembered locations in prefrontal cortex. PLoS Biol 2:e365. CrossRef Medline

Lebedev MA, Carmena JM, O'Doherty JE, Zacksenhouse M, Henriquez CS, Principe JC, Nicolelis MA (2005) Cortical ensemble adaptation to represent velocity of an artificial actuator controlled by a brain-machine interface. J Neurosci 25:4681-4693. CrossRef Medline

Lebedev MA, O’Doherty JE, Nicolelis MA (2008) Decoding of temporal intervals from cortical ensemble activity. J Neurophysiol 99:166-186. CrossRef Medline

Leergaard TB, Alloway KD, Pham TA, Bolstad I, Hoffer ZS, Pettersen C, 
Bjaalie JG (2004) Three-dimensional topography of corticopontine projections from rat sensorimotor cortex: comparisons with corticostriatal projections reveal diverse integrative organization. J Comp Neurol 478:306-322. CrossRef Medline

Lewis PA, Miall RC (2003) Brain activation patterns during measurement of sub- and supra-second intervals. Neuropsychologia 41:1583-1592. CrossRef Medline

Lewis PA, Miall RC (2006) A right hemispheric prefrontal system for cognitive time measurement. Behav Processes 71:226-234. CrossRef Medline

Maimon G, Assad JA (2006) A cognitive signal for the proactive timing of action in macaque LIP. Nat Neurosci 9:948-955. Medline

Manohar A, Flint RD, Knudsen E, Moxon KA (2012) Decoding hindlimb movement for a brain machine interface after a complete spinal transection. PLoS One 7:e52173. CrossRef Medline

Matell MS, Meck WH, Nicolelis MA (2003) Interval timing and the encoding of signal duration by ensembles of cortical and striatal neurons. Behav Neurosci 117:760-773. CrossRef Medline

Matell MS, Shea-Brown E, Gooch C, Wilson AG, Rinzel J (2011) A heterogeneous population code for elapsed time in rat medial agranular cortex. Behav Neurosci 125:54-73. CrossRef Medline

Mazurek ME, Roitman JD, Ditterich J, Shadlen MN (2003) A role for neural integrators in perceptual decision making. Cereb Cortex 13:1257-1269. CrossRef Medline

Merchant H, Georgopoulos AP (2006) Neurophysiology of perceptual and motor aspects of interception. J Neurophysiol 95:1-13. CrossRef Medline

Merchant H, Battaglia-Mayer A, Georgopoulos AP (2004a) Neural responses in motor cortex and area 7a to real and apparent motion. Exp Brain Res 154:291-307. CrossRef Medline

Merchant H, Battaglia-Mayer A, Georgopoulos AP (2004b) Neural responses during interception of real and apparent circularly moving stimuli in motor cortex and area 7a. Cereb Cortex 14:314-331. CrossRef Medline

Merchant H, Zarco W, Pérez O, Prado L, Bartolo R (2011) Measuring time with different neural chronometers during a synchronization-continuation task. Proc Natl Acad Sci U S A 108:19784-19789. CrossRef Medline

Merchant H, Harrington DL, Meck WH (2013a) Neural basis of the perception and estimation of time. Annu Rev Neurosci 36:313-336. CrossRef Medline

Mirabella G, Pani P, Ferraina S (2011) Neural correlates of cognitive control of reaching movements in the dorsal premotor cortex of rhesus monkeys. J Neurophysiol 106:1454-1466. CrossRef Medline

Mita A, Mushiake H, Shima K, Matsuzaka Y, Tanji J (2009) Interval time coding by neurons in the presupplementary and supplementary motor areas. Nat Neurosci 12:502-507. CrossRef Medline

Olds J (1965) Operant conditioning of single unit responses. Presented at the 23rd International Congress Physiological Sciences, Tokyo, pp. 372-380.

Rammsayer TH, Troche SJ (2014) In search of the internal structure of the processes underlying interval timing in the sub-second and the second range: a confirmatory factor analysis approach. Acta Psychol 147:68-74. CrossRef Medline

Renoult L, Roux S, Riehle A (2006) Time is a rubberband: neuronal activity in monkey motor cortex in relation to time estimation. Eur J Neurosci 23:3098-3108. CrossRef Medline

Reutimann J, Yakovlev V, Fusi S, Senn W (2004) Climbing neuronal activity as an event-based cortical representation of time. J Neurosci 24:32953303. CrossRef Medline

Rind FC, Simmons PJ (1997) Signaling of object approach by the DCMD neuron of the locust. J Neurophysiol 77:1029-1033. Medline

Rind FC, Simmons PJ (1999) Seeing what is coming: building collisionsensitive neurons. Trends Neurosci 22:215-220. CrossRef Medline

Roux S, Coulmance M, Riehle A (2003) Context related representation of timing processes in monkey motor cortex. Eur J Neurosci 18:1011-1016. CrossRef Medline

Salvioni P, Murray MM, Kalmbach L, Bueti D (2013) How the visual brain encodes and keeps track of time. J Neurosci 33:12423-12429. CrossRef Medline

Schultz W, Tremblay L, Hollerman JR (2003) Changes in behavior-related neuronal activity in the striatum due to learning. Trends Neurosci 26 : 321-328. CrossRef Medline

Scott SH (2004) Optimal feedback control and the neural basis of volitional motor control. Nat Rev Neurosci 5:532-546. CrossRef Medline

Song W, Ramakrishnan A, Udoekwere UI, Giszter SF (2009) Multiple types of movement-related information encoded in hindlimb/trunk cortex in rats and potentially available for brain-machine interface controls. IEEE Trans Biomed Eng 56:2712-2716. CrossRef Medline

Stenneken P, Aschersleben G, Cole J, Prinz W (2002) Self-induced versus reactive triggering of synchronous movements in a deafferented patient and control subjects. Psychol Res 66:40-49. CrossRef Medline

Stenneken P, Prinz W, Cole J, Paillard J, Aschersleben G (2006) The effect of sensory feedback on the timing of movements: evidence from deafferented patients. Brain Res 1084:123-131. CrossRef Medline

Storey JD, Taylor JE, Siegmund D (2004) Strong control, conservative point estimation and simultaneous conservative consistency of false discovery rates: a unified approach. J R Stat Soc B 66:187. CrossRef

Sugrue LP, Corrado GS, Newsome WT (2005) Choosing the greater of two goods: neural currencies for valuation and decision making. Nat Rev Neurosci 6:363-375. CrossRef Medline

Sun H, Frost BJ (1998) Computation of different optical variables of looming objects in pigeon nucleus rotundus neurons. Nat Neurosci 1:296-303. CrossRef Medline

Widajewicz W, Kably B, Drew T (1994) Motor cortical activity during voluntary gait modifications in the cat. II. Cells related to the hindlimbs. J Neurophysiol 72:2070-2089. Medline

Wittmann M (2013) The inner sense of time: how the brain creates a representation of duration. Nat Rev Neurosci 14:217-223. CrossRef Medline 